\title{
RANCANG BANGUN PENGGAJIAN KARYAWAN BERBASIS WEB PADA PT. SURGANYA MOTOR INDONESIA
}

\author{
Ria Wulandari ${ }^{1}$ \\ Aditya Giyantono $^{2}$ \\ Agus Gunawan ${ }^{3}$
}

\author{
Dosen STMIK Raharja Tangerang ${ }^{1,}$ Mahasiswa STMIK Raharja Tangerang ${ }^{2,3}$ \\ Jl.Jendral Sudirman No.40, Modernland, Tangerang 1,2,3 \\ Email : wulandari@raharja.info ${ }^{1}$, aditya.giyantono@ raharja.info ${ }^{2}$, \\ agus.gunawan@raharja.info ${ }^{3}$
}

\begin{abstract}
ABSTRAK
Komputer merupakan suatu alat untuk melakukan kegiatan dalam bidang administrasi atau tempat untuk menyimpan ribuan data yang bisa diproses sewaktu-waktu tanpa memerlukan waktu yang lama untuk melakukannya.Sistem penggajian merupakan suatu hal yang sudah sangat pokok pada kegiatan finansial pada sebuah instansi perusahaan maupun perindustrian, karena hal tersebut berpengaruh terhadap kinerja para karyawan.Pemberian gaji merupakan kegiatan rutin yang dilakukan bagi perusahaan sehingga merupakan pengeluaran perusahaan yang relatif besar karena itu diperlukan suatu sistem penggajian yang baik agar dalam pelaksanaan penggajian dari perhitungan sampai pembayaran dapat berjalan dengan efisien dan lancar. Sehingga dalam menetapkan gaji seorang pimpinan harus mengetahui tentang poduktifitas, jabatan atau golongan, lama kerja, dan prestasi kerja masing-masing karyawan. Dengan demikian, maka sistem penggajian PT. Surganya Motor Indonesia harus mendapatkan pengawasan dan penanganan yang tepat dalam pembayaran gaji agar tidak terjadi penyimpangan dan penyalahgunaan.Metode yang digunakan dalam penelitian ini yaitu metode pengumpulan data diantaranya, wawancara, observasi, dan studi pustaka. Metode analisa yang digunakan yaitu analisa SWOT, sedangkan metode perancangan menggunakan UML. Metode pengujiannya menggunakan metode black box. Sistem ini diharapkan dapat mengurangi kesalahan dalam perhitungan gaji karyawan dan dapat menyingkat waktu dalam perhitungan gaji karyawan. Sehingga dapat mempermudah mekanisme untuk menyelesaikan suatu permasalahan bagi pihak yang terkait dalam penerapan sistem penggajian karyawan pada PT. Surganya Motor Indonesia.
\end{abstract}

Kata kunci :Karyawan, Sistem Penggajian, Teknologi Informasi

\begin{abstract}
Computer is a tool to carry out activities in the field of administration or a place to store thousands of data that can be processed at any time without requiring a long time to do so.Payroll system is something that is very fundamental to the financial activities on a corporate or industrial establishments, because it affects the performance of the employee.Remuneration is a routine activity carried out for companies that are spending a relatively large company because it needed a good payroll system for the implementation of the payroll calculation until payment can be run efficiently and smoothly. So that in determining the salaries of the leaders should know about poduktifitas, office or class, length of work, and the work performance of each employee.Thus, the payroll system PT. Surganya Motor Indonesia must gain control and precise handling in the payment of salaries to prevent
\end{abstract}


fraud and abuse. The method used in this research is the method of data collection including interviews, observation, and literature. The analytical methods used are the SWOT analysis, while the method of design using UML. The test method using black box method.The system is expected to reduce errors in the calculation of salary and can save time in the calculation of employees' salaries. So as a facilitate a mechanism to solve a problem for those involved in the implementation of the payroll system employees at PT. Surganya Motor Indonesia.

\section{Keywords: Employees, Payroll Systems, Information Technology}

\section{PENDAHULUAN}

Kemajuan ilmu teknologi modern mempunyai dampak yang sangat begitu besar dalam kehidupan manusia, ini terbukti dengan banyak terciptanya alat-alat canggih yang dapat memudahkan atau meringankan pekerjaan manusia. Salah satu kemajuan teknologi yang telah menerobos kehidupan masyarakat adalah dengan adanya suatu peralatan canggih yang dikenal dengan nama "komputer".

Komputer merupakan suatu alat bantu yang dapat meringankan beban manusia dalam menangani dan memecahkan berbagai masalah dan kelemahan ditimbulkan dengan mengandalkan tenaga manusia, baik perusahaan maupun pemerintah, dan juga suatu alat yang memiliki kelebihan bila dibandingkan dengan mesin hitung biasa. Komputer merupakan suatu alat untuk melakukan kegiatan dalam bidang administrasi atau tempat untuk menyimpan ribuan data yang bisa diproses sewaktu-waktu tanpa memerlukan waktu yang lama untuk melakukannya. Sehingga dengan adanya komputer akan bisa menghasilkan informasi yang efisien sehingga dapat membantu dalam hal pengambilan keputusan.

PT. Surganya Motor Indonesia adalah sebuah perusahaan yang bergerak dibidang retail sparepart motor kendaraan roda dua, yang kegiatan utama menyalurkan dan memberikan produk terbaik untuk para konsumen. PT Surganya Motor Indonesia mempunyai banyak karyawan dan dalam hal penggajian belum dilakukan secara terkomputerisasi. Sehingga banyaknya terjadinya kesalahan. Untuk itu, maka diperlukan suatu sistem yang terkomputerisasi dalam rangka memberikan informasi kepada para karyawan dan pihak lain yang bersangkutan secara tepat, cepat dan akurat.

\section{METODE PENELITIAN}

\section{Metode Pengumpulan Data}

Untuk mendapatkan data yang benar-benar akurat (jelas mencerminkan maksudnya), relevan (mempunyai manfaat untuk pemakai), dan valid (sah) maka dikumpulkan sumber data dengan cara:

1. Sumber data primer

Data didapatkan dari pengamatan maupun pencatatan terhadap obyek penelitian, yaitu pada PT. Surganya Motor Indonesia.. Sumber data primer meliputi:

a. Observasi

Adalah suatu metode untuk mendapatkan data dengan melakukan pengamatan dan melaksanakan pencatatan sistematis terhadap unsur-unsur yang di teliti, melakukan tinjauan langsung ke divisi tempat penelitian.

b. Wawancara

Adalah suatu metode untuk mendapatkan data dan keterangan mengenai suatu hal dengan cara wawancara atau tanya jawab secara lisan yang dilakukan kepada pihakpihak yang terlibat.

2. Sumber data sekunder 
Adalah data yang diambil dari buku-buku, dokumentasi, dan literatur-literatur,meliputi:

a. Studi Kepustakaan

Adalah pengumpulan data dari buku-buku yang sesuai dengan tema permasalahan

yang dibahas, dan sumber-sumber lain yang sesuai dengan permasalahan yang

dibahas.

b. Studi Dokumentasi

Adalah pengumpulan data dari literatur-literatur dan dokumentassi dari internet, diktat dan sumber informasi lain yang berhubungan dengan permasalahan dibahas.

\section{KAJIAN PUSTAKA}

\section{Definisi Gaji atau upah}

Gaji merupakan pembayaran atas penyerahan jasa yang dilakukan karyawan yang dibayarkan secara tetap perbulan. Upah adalah pembayaran atas penyerahan jasa yang dilakukan oleh karyawan pelaksana (buruh) yang dibayarkan berdasarkan hari kerja, jam kerja, atau jumlah satuan produk yang dihasilkan oleh karyawan. [1]

\section{Definisi Gaji Pokok}

Gaji pokok adalah gaji dasar yang ditetapkan untuk melaksanakan satu jabatan atau pekerjaan tertentu pada golongan pangkat dan waktu tertentu. Gaji pokok di suatu perusahaan disusun menurut jenjang jabatan dan jenjang kepangkatan.[2]

\section{Definisi Jabatan}

Jabatan adalah kelompok pekerjaan atau tugas tugas dalam unit organisasi yang dalam pelaksanaannya memerlukan syarat-syarat tertentu yang sama atau hampir sama. Syaratsyarat yang diperlukan untuk melakukan pekerjaan pada jabatan tertentu berbeda dengan syarat yang diperlukan untuk melakukan pekerjaan pekerjaan pada jabatan lain.[2]

\section{Definisi Tunjangan}

Tunjangan adalah suplemen terhadap upah atau gaji pokok dalam fungsi, yaitu berkaitan dengan pelaksanaan tugas, dalam rangka fungsi sosial, dan sebagai insentif. Tunjangan yang berkaitan dengan pelaksanaan tugas adalah tunjangan jabatan, baik jabatan struktural maupun jabatan fungsional.[2]

\section{Definisi Sistem Penggajian atau Pengupahan}

Penggajian adalah suatu penerimaan sebagai imbalan dari pengusaha kepada karyawan untuk suatu pekerjaan atau jasa yang telah atau dilakukan dan dinyatakan atau dinilai dalam bentuk uang yang ditetapkan atas dasar suatu persetujuan atau peraturan perundang-undangan serta dibayarkan atas dasar suatu perjanjian kerja antara pengusaha dengan karyawan termasuk tunjangan, baik untuk karyawan itu sendiri maupun untuk keluarga.

Sistem penggajian merupakan kerangka bagaimana upah diatur dan ditetapkan sistem. Pengupahan di Indonesia pada umumnya didasarkan kepada tiga fungsi upah yaitu

a. Menjamin kehidupan yang layak bagi pekerja dan keluarganya

b. Mencerminkan imbalan atas hasil kerja seseorang

c. Menyediakan insentif untuk mendorong peningkatan produktivitas kerja.[3]

\section{LITERATURE RIVIEW}

Banyak penelitian yang dilakukan sebelum dalam pembuatan sistem penggajian karyawan. Agar pengembangan sistem ini dapat dilakukan dengan optimal. Sehingga menghindari pembuatan ulang dan mengidentifikasi suatu meotde penelitian yang pernah dilakukan sebelumnya. Mengetahui orang lain yang memiliki spesialisasi penelitian yang sama dibidang ini, beberapa literature riview tersebut adalah sebagai berikut:

a. Penelitian yang dilakukan oleh Adi Aminudin (2015). Dalam penelitian yang berjudul "Sistem Informasi Penggajian Pegawai Pada Kantor Kecamatan Nawangan Kabupaten 
Pacitan", metode yang digunakan yaitu dengan melaksanakan pengamatan, wawancara, dokumentasi, studi pustaka, kuisioner, analisis dan perancangan sistem informasi dilanjutkan dengan pembuatan sistem informasi penggajian pegawai pada kantor kecamatan Nawangan. Dengan sistem informasi penggajian pegawai pada kantor kecamatan Nawangan Kabupaten Pacitan, akan mempermudah sistem penggajian yang ada disana dan mengurangi kesalahan dalam perhitungan gaji pegawai. Hasil dari penelitian ini adalah untuk memberikan kemudahan dalam mengelola gaji pegawai dengan memiliki media penyimpanan yang lebih efektif.[4]

b. Penelitian yang dilakukan oleh Fio Alfiandi (2014). Dalam penelitian yang berjudul "The Implementation of Payroll Accounting System as an Effort to Improve The System of Internal Control (a Study at PDAM Kota Malang)". (Penerapan Sistem Penggajian Akuntansi Sebagai Upaya Meningkatkan Sistem Pengendalian Internal (Studi di PDAM Kota Malang)), dengan menggunakan metode deskriptif, peneliti memperoleh data yang relevan dengan menggunakan metode wawancara dan dokumentasi. Hasilnya menunjukkan bahwa sistem ini diimplementasikan baik dan mendukung pengendalian internal. Hal ini dibuktikan dengan keterlibatan fungsi-fungsi terkait dalam pengolahan penggajian secara efektif. Juga, otoritas setiap pekerjaan jelas dan mengikuti prosedur. Studi ini menunjukkan perusahaan untuk menambahkan informasi yang lebih spesifik terkait dengan potongan pajak penghasilan dari upah bersih karyawan. Penelitian ini juga merekomendasikan perusahaan untuk menerapkan flowchart lebih lengkap dalam sistem penggajian.[5]

c. Penelitian yang dilakukan oleh Ade Rizal Winanda A. (2015). Dalam penelitian yang berjudul "Salary Information System(Case Study at SME's Tiara Handicraft)",metode penelitian dalam penelitian ini adalah penelitian deskriptif dengan pendekatan studi kasus. Analisa data akan melibatkan analisis terhadap karakteristik dan masalah terhadap sistem yang telah ada. Hasil dari penelitian ini adalah desain sistem baru yang dapat digunakan untuk menyelesaikan permasalahan dari sistem yang sudah ada. Proses pembuatan sistem baru adalah membuat desain logika dan fisik sistem. Selanjutnya membuat desain databasesebagaipusat data dan melakukan proses koding. Proses akhir dari desain sistem adalah pemeriksaan sistem. Proses pemeriksaan sangat penting untuk memeriksa kinerja sistem agar berjalan sesuai tujuan desain awal atau masih adanya buguntuk diperbaiki.[6]

d. Penelitian yang dilakukan oleh Saiful Nur Arif (2011). Dalam penelitian yang berjudul "Sistem Informasi Penggajian guru Pada SMA PAB 11 Lubuk Pakam", hasil dari program ini adalah pertama menggunakan Microsoft Visual Basic 6.0, sebuah sistem informasi yang sangat mudah dimengerti dapat dibuat sebagai sangat efisien. Kedua program yang dirancang memberikan klarifikasi dari sistem yang ada dan dapat membantu perusahaan mengelola data karyawan dan sistem penggajian secara efisien dan efektif. Ketiga sistem penggajian guru menggunakan bahasa pemograman Visual Basic 6.0 dan didukung oleh Microsoft Acces 2003 sebagai pembuatan laporan sistem. Keempat sistem yang menghubungkan dari Microsoft Visual Basic 6.0 dengan Microsoft Acces 2003 menggunakan teknologi akses yaitu ADO (Active Data Object) dan sebagainya, sistem informasi dapat diandalkan jika sudah bebas dari kesalahan data atau kesalahan diproses menjadi bentuk yang berarti untuk penerima dan deduktif menguntungkan dimasa kini dan dimasa depan. Kelima desain sistem informasi yang telag dibuat dapat membantu sekolah untuk menerapkan sistem penggajian guru, sehingga menjadi lebih cepat, akurat, dan efisien. Meskipun data yang diperoleh cukup banyak.[7]

e. Penelitian yang dilakukan oleh Ivone Orelia Wibowo (2012). Dalam penelitian yang 
berjudul "Perancangan Sistem Informasi Penggajian Terkomputerisasi Dalam rangka Meningkatkan Efektivitas, Efisiensi, dan Pengendalian Internal Pada Yayasan Lazaris". Penelitian ini dilakukan dalam bentuk studi kasus, jenis data yang dikumpulkan adalah data kualitatif yang berasal dari internal organisasi. Metode yang digunakan dalam pengumpulan data adalah wawancara dan dokumentasi. Unit analisis dalam penelitian ini adalah catatan prosedur, dokumen, dan gaji. Teknik analisis data yang digunakan adalah analisis sistem, konsep desain, dan desain fisik. Penelitian telah dilakukan, menghasilkan desain sistem informasi penggajian komputerisasi dalam rangka meningkatkan efektifitas, efisiensi, dan kontrol internal pada Lazaris Foundation, desain penggajian sistem informasi terkomputerisasi meliputi konsep desain terdiri dari diagram alur sistem, Data Flow Diagram (DFD), Entity Relationship Diagram (ERD), dan desain fisik yang terdiri dari output desain, masukan, database, dan akses yang menghasilkan program aplikasi penggajian.[8]

Perbedaan dengan penelitian terdahulu yaitu pada penelitian ini sangat membantu sekali pihak PT. SURGANYA MOTOR INDONESIA dalam hal perhitungan gaji karyawan $\mathrm{d}$ an sistem ini diharapkan dapat mengurangi kesalahan dalam perhitungan gaji karyawan, sehingga dapat mempermudah mekanisme untuk menyelesaikan suatu permasalahan bagi pihak yang terkait dalam penerapan sistem penggajian karyawan. Aplikasi ini merupakan penelitian dalam hal penggajian karyawan yang sudah berbasis web dan bisa diakses secara online.

\section{PEMBAHASAN}

A. Use Case Diagram Sistem Yang Diusulkan Menggunakan UML

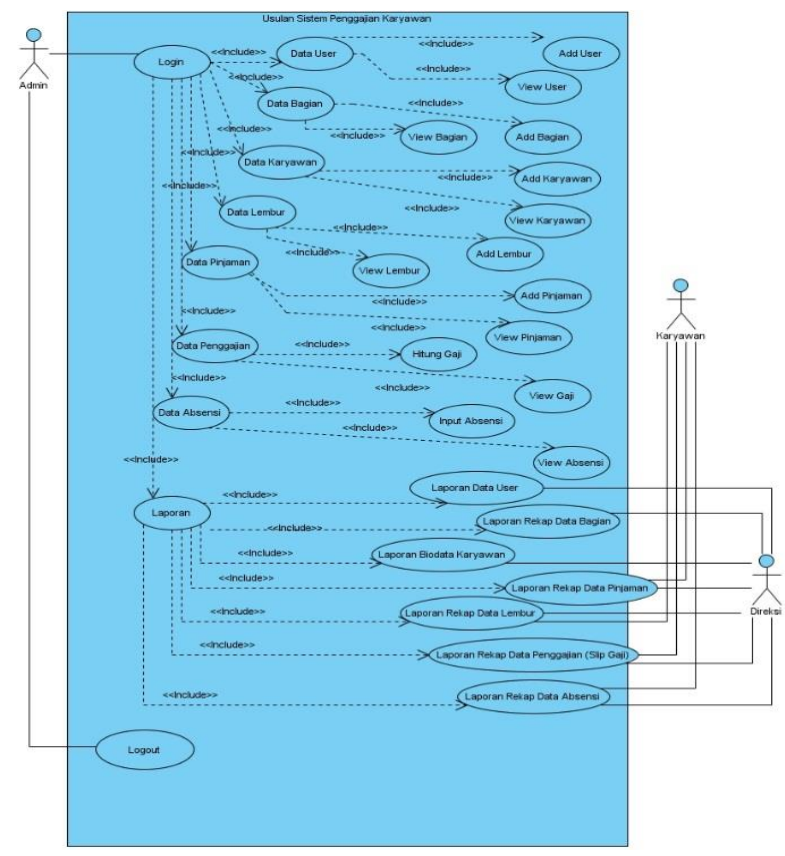

Gambar 1. Use Case Diagram Sistem Penggajian Karyawan

Berdasarkan gambar 1 Use Case Diagram pada sistem penggajian pegawai terdapat :

a. 1 sistem yang mencakup seluruh pengolahan data.

b. 3 actoryang melkaukan kegiatan yaitu Admin, Karyawan, Direksi. 
c. 2 usecase yang dilakukan yaitu Login, Logout.

d. 29 include yaitu Data User, Add User, View User, Data Bagian, Add Bagian, View Bagian, Data Karyawan, Add Karyawan, View Karyawan, Data Lembur, Add Lembur, View Lembur, Data Pinjaman, Add Pinjaman, View Pinjaman, Data Penggajian, Add Penggajian, View Penggajian, Data Absensi, Input Absensi, View Absensi, Laporan, Laporan Data User, Laporan Rekap Data Bagian, Laporan Biodata Karyawan, Laporan Rekap Data Pinjaman, Laporan Rekap Data Lembur, Laporan Rekap Data Penggajian (Slip Gaji), Laporan Rekap Data Absensi.

\section{B. Squence Diagram Yang Diusulkan}

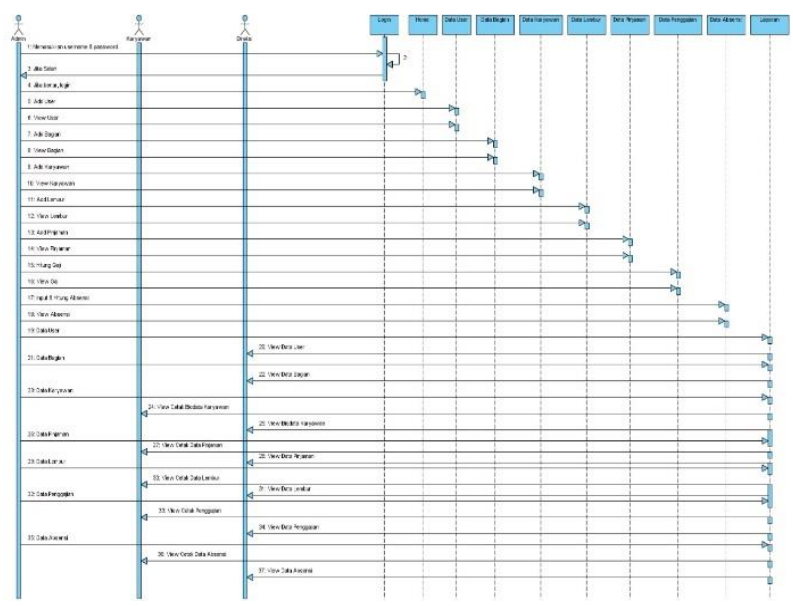

Gambar 2. Sequence Diagram Sistem Penggajian Karyawan Berdasarkan gambar 2 Sequence Diagram SistemPenggajian Karyawan terdapat:

a. 3 actor yang melakukan kegiatan yaitu Admin, Karyawan, dan Direksi.

b. 5 lifeline antar muka yang saling berinterkasi, yaitu Login, Home, Data User, Data Bagian, Data Karyawan, Data Lembur, Data Pinjaman, Data Penggajian, Data Absensi, Laporan.

c. 37 message, spesifikasi dari komuniksi antar objek yang membuat informasi aktifitas.

\section{Activity Diagram Yang Diusulkan}

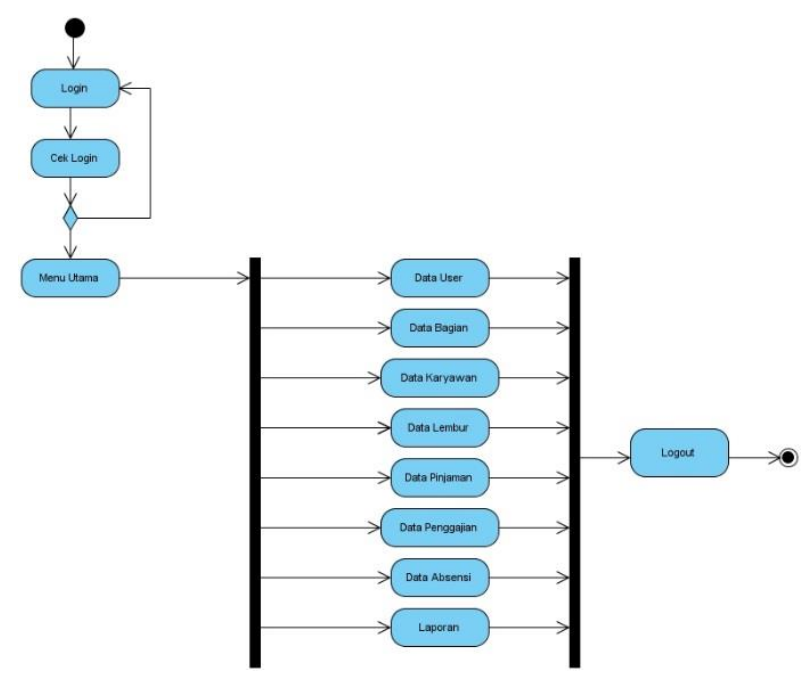

Gambar 3. Activity Diagram Sistem Penggajian Karyawan 
Berdasarkan gambar 3 Activity Diagram Sistem Penggajian Karyawan terdapat :

a. 1 initial node yang merupakan mengawali kegaiatan.

b. 12 action state dari sistem yang mencerminkan eksekusi suatu aksi, yaitu Login, Cek Login, Menu Utama, Data User, Data Bagian, Data Karyawan, Data Lembur, Data Pinjaman, Data Penggajian, Data Absensi, Laporan, Logout.

c. 1 decision node, digunakan dalam pengambilan keputusan.

d. 2 fork node

e. 1 final node, yang merupakan akhir kegiatan.

\section{IMPLEMENTASI}

Rancangan tampilan berbasis web. Rancangan ini dibuat dengan menggunakan Macromedia Dreamweaver dan bahasa pemograman PHP. Merancang aplikasi dengan menggunakan program open source (PHP) dan dapat lebih mudah dalam pengembangannya karena dapat berjalan disemua platform.

Berikut ini adalah tampilan sistem penggajian karyawan:

1. Tampilan Halaman Menu Login

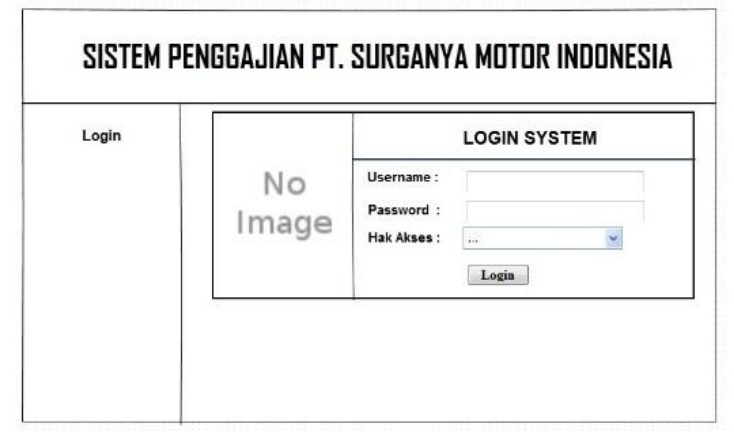

Gambar 4. Tampilan Login

Halaman login merupakan tampilan menu yang pertama kali tampil ketika user menjalankan sistem ini. Pada halaman ini user diminta untuk memasukkan username, password, dan hak akses. Sebagai apa, sebagai mengakses halaman utama. Didalam sistem ini hanya memiliki hak akses yaitu kepala finance\&accounting, karyawan, dan direksi.

2. Tampilan Halaman Home

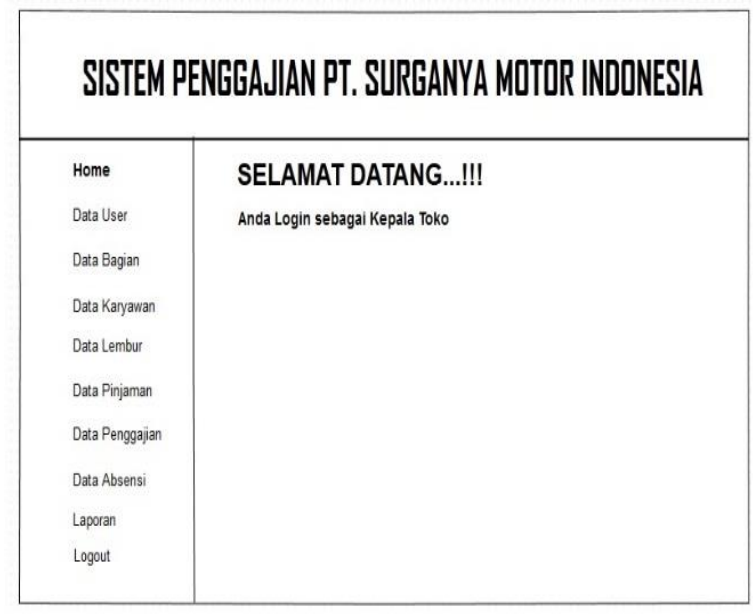

Gambar 5. Tampilan Home 
Halaman home merupakan tampilan menu utama setelah user melakukan login pada halaman menu login. Pada tampilan home ini terdapat menu data user, data bagian, data karyawan, data lembur, data pinjaman, data penggajian, data absensi, laporan dan logout.

3. Tampilan Halaman Menu Perhitungan Data Penggajian

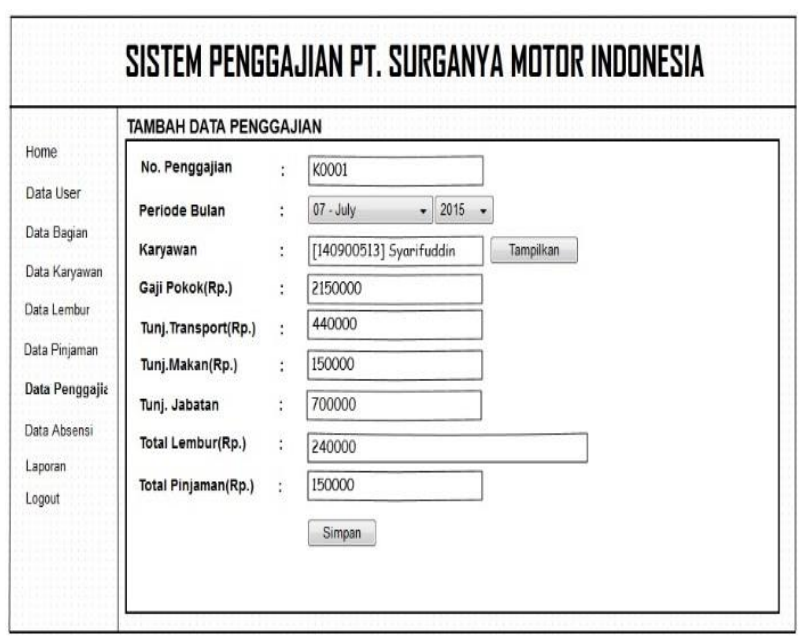

Gambar 6. Menu Perhitungan Data Penggajian

Halaman menu perhitungan data penggajian merupakan tampilan menu yang berisikan seluruh data-data yang akan diproses dalam melakukan perhitungan gaji pada setiap karyawan. Menu ini terdiri dari no pengajuan, periode bulan, nik dan nama karyawan, gaji pokok, tunjangan transportasi, tunjangan makan, tunjangan jabatan, total lembur dan total pinjaman.

4. Tampilan Halaman Slip Gaji

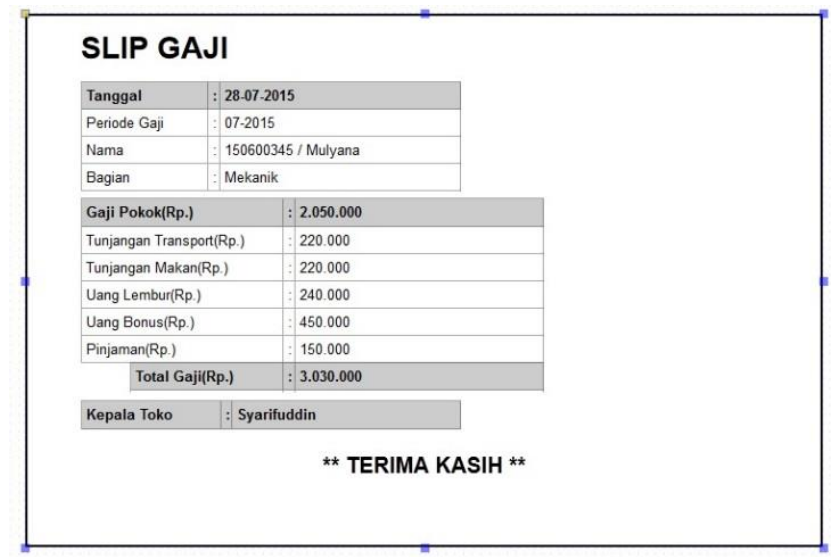

\section{Gambar 7. Tampilan Slip Gaji}

Halaman slip gaji merupakan tampilan menu laporan penggajian setiap karyawan. Menu ini terdiri dari tanggal, periode gaji, nama, bagian, gaji pokok, tunjangan transportasi, tunjangan makan, uang lembur, uang bonus, pinjaman, total gaji dan nama kepala took. 


\section{Kesimpulan}

Sistem penggajian karyawan yang diterapkan di PT. Surganya Motor Indoensia belum sepenuhnya cukup maksimal karena masih dilakukan dengan cara manual yaitu dengan menggunaknan microsoft excel sehingga membutuhkan waktu yang cukup lama dalam pengerjaannya dan dikhawatirkan sewaktu-waktu adanya kesalahan dalam perhitungan gaji karyawan. Maka dari itu dibuatlah sistem penggajian karyawan yang terintegrasi dengan web, yang diharapkan dapat mengurangi kesalahan dalam perhitungan gaji karyawan dan dapat menyingkat waktu dalam perhitungan gaji karyawan. Sehingga dapat mempermudah mekanisme untuk menyelesaikan suatu permasalahan bagi pihak yang terkait dalam penerapan sistem penggajian karyawan pada PT. Surganya Motor Indonesia. Dan sistem yang dirancang sebagai aplikasi penggajian pada PT. Surganya Motor Indonesia, dirancang khusus agar dapat menghitung kategori penghasilan karyawan yang dapat menampilkan laporan data bagian atau jabatan, laporan data karyawan, laporan daftar gaji dan laporan slip gaji karyawan dengan tampilan print out

\section{DAFTAR PUSTAKA}

1. Mulyadi. 2001. Sistem Akuntansi. Jakarta: Salemba Empat.

2. Samsudin, Sadili. 2006. Manajemen Sumber Daya Manusia. Bandung: Pustaka Setia.

3. Sumarsono. Sonny. 2003. Ekonomi Manajemen Sumber Daya Manusia dan Ketenagakerjaan. Yogyakarta: Graha Ilmu.

4. Aminudin, Adi, Bambang Eka Purnama, Indah Uly Wardayati. 2015. "Sistem Informasi

5. Penggajian Pegawai Pada Kantor Kecamatann Nawangan Kabupaten Pacitan”. Journal Speed Vol.7 No.3.

6. Alfiandi, Fio, Kertahadi, Nila Firdausi Nuzula. 2014. "The Implementation of Payroll Accounting System As An Effort To Improve the System of Internal Control (a Study at PDAM Kita Malang)”. Jurnal Administrasi Bisnis Vol.14 No.1 September 2014. Malang: Universitas Brawijaya.

7. A, Ade Rizal Winanda, Kertahadi, Devi Farah Azizah. 2015. "Salary Information System (Case Study at SME's Tiara Handicraft)". Jurnal Administrasi Bisnis Vol.3 No.1 Maret 2015. Malang”. Universitas Brawijaya.

8. Arif, Saiful Nur, Ishak. 2011. "Sistem Informasi Penggajian Guru Pada SMA PAB 11 Lubuk Pakam”. Jurnal SAINTIKOM Vol.10 No.3 September 2011. Sumatera Utara: STMIK Triguna Dharma.

9. Wibowo, Avone Orelia. 2012. "Perancangan Sistem Informasi Penggajian Terkomputerisasi Dalam Rangka Meningkatkan Efektivitas, Efisiensi, dan Pengendalian Internal Pada Yayasan Lazaris". Jurnal Ilmiah Mahasiswa Akuntansi Vol.1 No.1 Januari 2012.

10. Julyandi, Juni Nurmasari, Memen Akbar. 2012. "Rancang dan Bangun Sistem Informasi Penggajian Karyawan (Studi Kasus PT. JNE)”. Jurnal Sistem Informasi Vol.1 September 2012. Pekanbaru: Politeknik Caltex Riau. 